\title{
Risks of myeloid malignancies in patients with autoimmune conditions
}

\author{
LA Anderson ${ }^{*, 1}$, RM Pfeiffer ${ }^{2}$, O Landgren ${ }^{2,3}$, S Gadalla ${ }^{2}$, SI Berndt ${ }^{2}$ and EA Engels ${ }^{2}$ \\ 'Centre for Public Health, Queen's University Belfast, Northern Ireland BTI2 6B], UK; '2Division of Cancer Epidemiology and Genetics, National Cancer \\ Institute, Rockville, MD 20892, USA; ${ }^{3}$ Medical Oncology Branch, Center for Cancer Research, National Cancer Institute, Bethesda, MD, USA
}

\begin{abstract}
Autoimmune conditions are associated with an elevated risk of lymphoproliferative malignancies, but few studies have investigated the risk of myeloid malignancies. From the US Surveillance Epidemiology and End Results (SEER)-Medicare database, I 3486 myeloid malignancy patients (aged 67+ years) and 160086 population-based controls were selected. Logistic regression models adjusted for gender, age, race, calendar year and number of physician claims were used to estimate odds ratios (ORs) for myeloid malignancies in relation to autoimmune conditions. Multiple comparisons were controlled for using the Bonferroni correction $(P<0.0005)$. Autoimmune conditions, overall, were associated with an increased risk of acute myeloid leukaemia (AML) (OR I.29) and myelodysplastic syndrome (MDS, OR 1.50). Specifically, AML was associated with rheumatoid arthritis (OR I.28), systemic lupus erythematosus (OR 1.92), polymyalgia rheumatica (OR I.73), autoimmune haemolytic anaemia (OR 3.74), systemic vasculitis (OR 6.23), ulcerative colitis (OR I.72) and pernicious anaemia (OR 1.57). Myelodysplastic syndrome was associated with rheumatoid arthritis (ORI.52) and pernicious anaemia (OR 2.38). Overall, autoimmune conditions were not associated with chronic myeloid leukaemia (OR 1.09) or chronic myeloproliferative disorders (OR I.I5). Medications used to treat autoimmune conditions, shared genetic predisposition and/or direct infiltration of bone marrow by autoimmune conditions, could explain these excess risks of myeloid malignancies.

British Journal of Cancer (2009) I 00, 822 -828. doi: I0.1038/sj.bjc.6604935 www.bjcancer.com
\end{abstract}

(c) 2009 Cancer Research UK

Keywords: autoimmune conditions; myeloid leukaemia; myelodysplastic syndrome; chronic myeloproliferative diseases

The aetiology of myeloid malignancies, a heterogeneous group of disorders including acute myeloid leukaemia (AML), chronic myeloid leukaemia (CML), myelodysplastic syndrome (MDS) and chronic myeloproliferative disorders (MPDs), remains largely unknown. The main risk factors identified for AML are cigarette smoking (Kasim et al, 2005; Xu et al, 2007) and exposure to benzene or ionising radiation (Descatha et al, 2005). Chronic myeloid leukaemia arises from a translocation $\mathrm{t}(9 ; 22)$ ( $\mathrm{q} 34 ; \mathrm{q} 11)$, known as the Philadelphia chromosome, and is thought to be associated with radiation exposure (Preston-Martin et al, 1989). Myelodysplastic syndrome is a heterogeneous clonal haematological disorder that can progress to AML. Cigarette smoking (Nisse et al, 2001), solvent exposure (Nisse et al, 2001) and agricultural exposures (Strom et al, 2005) have all been associated with an increased risk of MDS, and senescence of the haematopoietic system is thought to play a role in its development (Dalamaga et al, 2002). Less is known about the causes of MPDs, including polycythemia vera and essential thrombocythemia.

Immune perturbations, including autoimmune diseases, have been associated with an increased risk of haematological malignancies. Although reported more commonly for lymphopro-

* Correspondence: Dr LA Anderson, Cancer Epidemiology and Prevention Research Group, Centre for Clinical and Population Sciences, Queen's University Belfast, Mulhouse Building, Grosvenor Road, Belfast, BTI2 6B], Northern Ireland, UK; E-mail: I.anderson@qub.ac.uk

Received I December 2008; revised 19 January 2009; accepted 19 January 2009 liferative neoplasms (Zintzaras et al, 2005; Ekstrom Smedby et al, 2008), increased risks in persons with autoimmune conditions have also been noted for myeloid malignancies, including AML and CML (Zheng et al, 1993; Askling et al, 2005b). Autoimmune conditions, which occur commonly in patients with MDS (Voulgarelis et al, 2004), have also been reported to precede MDS (Dalamaga et al, 2002). Using data from the Surveillance Epidemiology and End Results (SEER)-Medicare Assessment of Hematopoietic Malignancy Risk Traits (SMAHRT) study, we investigated whether autoimmune conditions were associated with subsequent risks of AML, CML, MDS and MPDs.

\section{MATERIALS AND METHODS}

The SMAHRT study is a population-based case-control study of haematopoietic malignancies using SEER-Medicare data (Warren et al, 2002; Anderson et al, 2008). The SEER program collects data on cancer diagnoses from multiple US sites since 1973 and currently covers $\sim 25 \%$ of the US population (Warren et al, 2002). Medicare provides federally funded health insurance for persons aged 65 years and older in the United States. All Medicare beneficiaries are entitled to Part A coverage, which includes hospital inpatient care. Approximately $96 \%$ of participants subscribe to Part B coverage, which covers both physician and outpatient services. The SEER-Medicare database has demographic and clinical information from SEER on cancer patients through December 2002, linked to their Medicare enrolment and claims data (Part A claims: 1986-2002; Part B claims: 1991-2002) 
(Warren et al, 2002). In addition, the Medicare data are available for a 5\% random sample of all Medicare beneficiaries without cancer residing in SEER areas.

The SMAHRT study includes, as cases, those individuals with a SEER diagnosis of a first primary haematopoietic malignancy $(n=93780)$ between 1987 and 2002 . We restricted this analysis to persons with a myeloid malignancy $(n=13486)$. Cases were classified into the following categories: AML (ICD-03 codes: 9840, 9861, 9866, 9867, 9870-9874, 9891, 9895-9897, 9910, 9920, 9930, 9931), CML (ICD-03: 9863, 9875, 9876), MDS (ICD-03: 9945, 9980, 9982, 9983, 9985, 9986, 9989) and MPD (ICD-03: 9741, 9742, 9750, 9754, 9755, 9756, 9757, 9950, 9960, 9961-9964, 9975). As MDS and MPD were not reportable to SEER registries until 2001 (Jaffe et al, 2001), only cases diagnosed in 2001 and 2002 were included ( $n=2471$ and $n=1017$, respectively). Cases were required to be aged 67-99 years at diagnosis of malignancy and to have at least 12 months of Part A, Part B and non-HMO Medicare coverage before diagnosis to ensure adequate time for accrual of Part A (and where applicable Part B) Medicare claims to ascertain the occurrence of autoimmune conditions. Persons diagnosed with malignancy only at autopsy or by a death certificate and those with human immunodeficiency virus infection were excluded.

The SMAHRT study includes two controls per haematopoietic malignancy case, selected from the $5 \%$ random sample of Medicare beneficiaries who were alive, free of any malignancy, and had at least 12 months of prior Medicare coverage as of 1 July in the calendar year of selection. Controls were frequency matched to haematopoietic malignancy cases by the calendar year of diagnosis, age in five categories $(67-69,70-74,75-79,80-84$ and 85-99 years) and gender. A person could be selected multiple times as a control for cases in different calendar years. All the SMAHRT study controls $(n=160086)$ were included in the AML and CML analyses. Only controls selected in 2001 and 2002 $(n=42886)$ were included in the MDS and MPD analyses.

We used hospital, physician and outpatient Medicare claims to assess whether individuals had any of the 27 specified autoimmune conditions (see Table 2). In assessing exposures, we required that the autoimmune condition was specified on at least one hospital claim, or at least two-physician or outpatient claims at least 30 days apart. Claims occurring during the 12-month period before case diagnosis-control selection were excluded to minimise the possibility that diagnoses of autoimmune conditions would be over-represented in cases because of ascertainment during the work-up for the malignancy.

\section{Statistical analysis}

Unconditional logistic regression was used to calculate the odds ratios (ORs) and 95\% confidence intervals (CIs), to assess the association of autoimmune conditions with myeloid malignancies separately for cases of each type compared with that in controls. We accommodated in the variance computation for the ORs the fact that each case subtype was compared with the same control population, that some controls later served as cases and the repeat selection of individuals as controls (Anderson et al, 2008). The AML and CML analyses were adjusted for age (using the categories of $67-69,70-74,75-79,80-84$, and $85-99$ years), gender, year of diagnosis/selection (1987-1996, 1997-1999, 2000-2001, 2002), race (white, other/unknown) and, as a measure of overall healthcare utilisation, the number of physician claims more than 12 months before diagnosis/selection (quartiles: $0-20,21-57,58-$ $127, \geqslant 128)$. The MDS and MPD analyses were adjusted for the same factors, except that the year of diagnosis/selection was included in models as two categories (2001 and 2002). As some myeloid malignancies, particularly MDS and MPD, can be chronic conditions, we conducted additional analyses excluding the 2 and 5 years before the diagnosis date of cases and the selection date of controls to ensure that the autoimmune conditions preceded MDS and MPD.

As we conducted 108 separate analyses to investigate the associations between 27 autoimmune conditions and 4 myeloid malignancies, we considered the impact of multiple testing on our findings. Although we indicate associations significant at a nominal significance level of $P=0.05$, we especially highlight in the tables and in the Discussion section those associations that were significant at a $P$-value of 0.0005 , which incorporates a Bonferroni correction.

\section{RESULTS}

This study included 13486 cases with a myeloid malignancy, which comprised 7824 individuals with AML, 2174 with CML, 2471 with MDS and 1017 with MPD. Compared with controls, cases were more likely to be male (except for MPD, in which cases were more likely to be female) and of white race. The median age at diagnosis/ selection was similar for the myeloid malignancy cases and controls. For each myeloid neoplasm, cases had more prior physician, outpatient and hospital claims than controls (Table 1).

As shown in Table 2, having any autoimmune condition was associated with an increased risk of AML (OR 1.29). Specifically, AML was associated positively with several autoimmune conditions at the $P<0.05$ significance level, including rheumatoid arthritis (OR 1.28), systemic lupus erythematosus (OR 1.92), polymyalgia rheumatica (OR 1.73), autoimmune haemolytic anaemia (AIHA) (OR 3.74), systemic vasculitis (OR 6.23), giant cell arteritis (OR 1.61), ulcerative colitis (OR 1.72) and pernicious anaemia (OR 1.57). Chronic myeloid leukaemia was increased with polymyalgia rheumatica (OR 1.79), dermatomyositis/polymyositis (OR 3.97), AIHA (OR 5.23) and coeliac disease (OR 4.19) (Table 2).

Overall, MDS was associated with having an autoimmune condition (OR 1.50) and specifically with rheumatoid arthritis (OR 1.52), Sjögren's syndrome (OR 1.78), systemic lupus erythematosus (OR 1.82), polymyalgia rheumatica (OR 1.47), AIHA (OR 4.12), chronic rheumatic heart disease (OR 1.28), polyarteritis nodosa (OR 4.31), discoid lupus erythematosus (OR 2.06) and pernicious anaemia (OR 2.38). In comparison, MPD was only associated with AIHA (OR 11.9), localised scleroderma (OR 2.34) and Crohn's disease (OR 2.18).

As MDS and MPD are often chronic diseases that may go unrecognised for several years, we conducted a sensitivity analysis excluding claims within 2 or 5 years of diagnosis. Compared with controls, MDS cases more commonly had rheumatoid arthritis (OR 1.52), polymyalgia rheumatica (OR 1.53) and pernicious anaemia (OR 1.68) reported more than 5 years before the diagnosis/selection (Table 3). Similiarly, localised scleroderma remained associated significantly with MPD when the 2-year or 5-year period before diagnosis was excluded (ORs 2.73 and 3.27, respectively) (Table 3 ).

Associations that remained significant after using a Bonferroni correction $(P<0.0005)$ are highlighted in Table 2 . These included rheumatoid arthritis, systemic lupus erythematosus, polymyalgia rheumatica, AIHA, systemic vasculitis, ulcerative colitis and pernicious anaemia with AML; dermatomyositis/polymyositis with CML; rheumatoid arthritis and pernicious anaemia with MDS; and AIHA with MPD.

\section{DISCUSSION}

In this large study of 13486 individuals with a myeloid malignancy, we investigated systematically the associations with a range of preceding autoimmune conditions. Overall, having an autoimmune condition was associated with an increased risk of AML and MDS, but not CML or MPD. Given the large number of 
Table I Characteristics of cases with myeloid malignancies and controls in the SMAHRT study

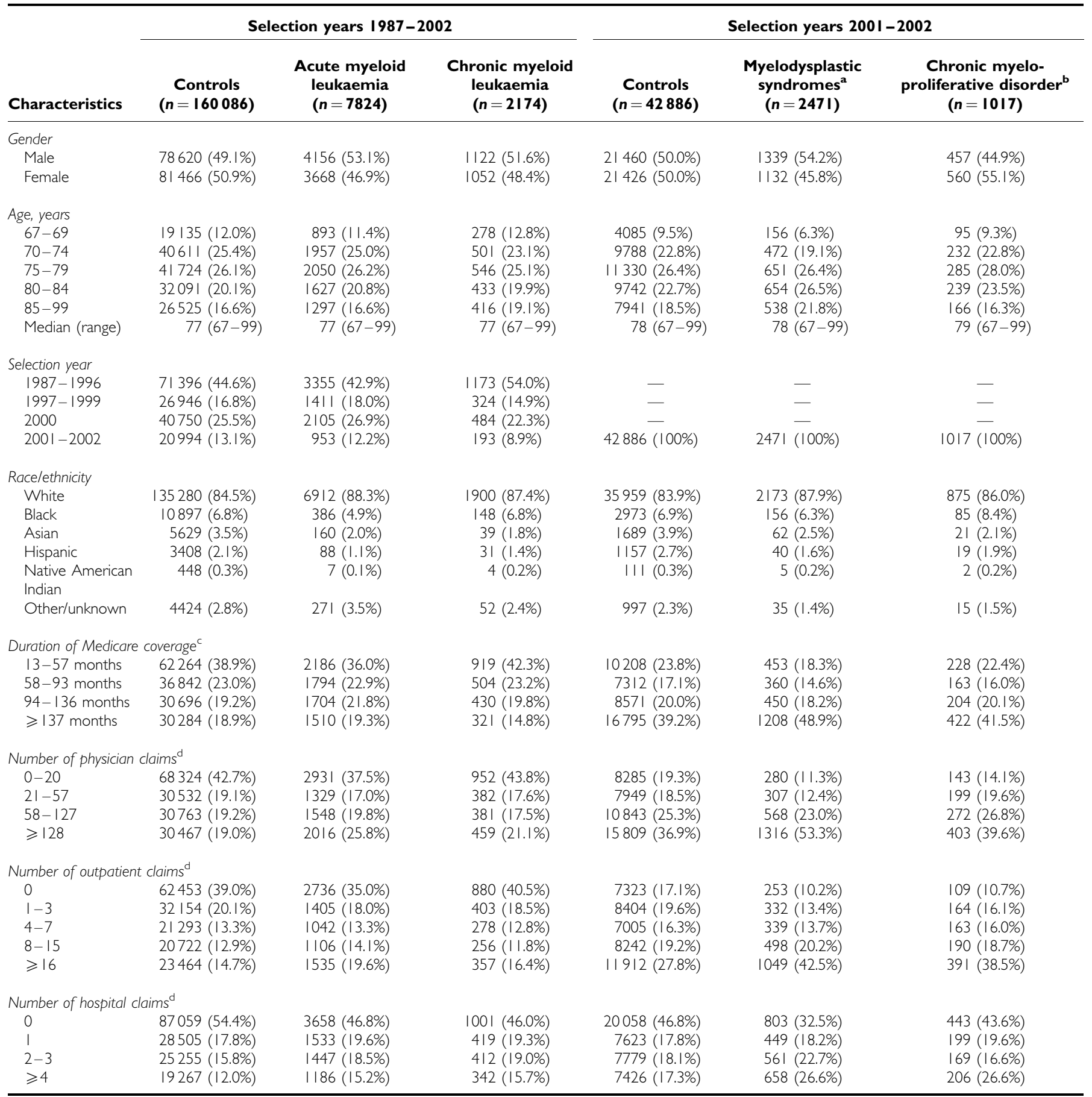

SMAHRT = Surveillance Epidemiology and End Results (SEER)-Medicare Assessment of Hematopoietic Malignancy Risk Traits. ${ }^{a}$ This category includes patients with refractory anaemia, refractory cytopenia with multilineage dysplasia, myelodysplastic syndrome with $5 \mathrm{q}$ deletion and myelodysplastic syndrome, not otherwise specified, diagnosed during 200 I-2002. 'This category includes patients with chronic neutrophilic leukaemia, chronic esinophilic leukaemia, chronic myeloproliferative disease not otherwise specified, chronic idiopathic myelofibrosis, essential thrombocythemia, polycythemia vera, mastocytosis and neoplasms of histiocytes and accessory lymphoid cells diagnosed during $200 \mathrm{I}-2002 .{ }^{c}$ Duration of coverage refers to simultaneous coverage by Part A and Part B while the individual was not enroled in a health maintenance organisation. ${ }^{\mathrm{d} T}$ The number of claims excludes the 12 months before haematopoietic malignancy diagnosis (cases) or selection (controls).

comparisons, we focus here on associations that were significant at a $P$-value cutoff provided by the Bonferroni method $(P<0.0005)$.

We observed significantly increased risks of AML and MDS associated with rheumatoid arthritis. Supporting this observation, Askling et al (2005b) found two-fold increased risks of AML and
CML in a large Swedish cohort study of patients hospitalised for rheumatoid arthritis. Although MDS is a chronic condition, we saw an association with rheumatoid arthritis even after excluding the 5 -year period before diagnosis/selection, arguing against reverse causality (i.e., that undiagnosed MDS caused rheumatoid arthritis). 
Table 2 Associations between autoimmune conditions and risk of myeloid malignancies

\begin{tabular}{|c|c|c|c|c|c|}
\hline $\begin{array}{c}\text { Controls } \\
(n=160086)\end{array}$ & $\begin{array}{c}\text { Acute myeloid } \\
\text { leukaemia }(n=7824)\end{array}$ & $\begin{array}{c}\text { Chronic myeloid } \\
\text { leukaemia }(n=2174)\end{array}$ & $\begin{array}{l}\text { Controls } \\
(n=42886)\end{array}$ & $\begin{array}{c}\text { Myelodysplastic } \\
\text { syndromes }(n=247 I)\end{array}$ & $\begin{array}{c}\text { Chronic } \\
\text { myeloproliferative } \\
\text { disorder }(n=1017)\end{array}$ \\
\hline
\end{tabular}

\begin{tabular}{|c|c|c|c|c|c|c|c|c|c|c|}
\hline $\begin{array}{l}\text { Autoimmune } \\
\text { conditions }\end{array}$ & No. & No. & OR $(95 \% \mathrm{CI})^{\mathrm{a}}$ & No. & OR $(95 \% \mathrm{CI})^{\mathrm{a}}$ & No. & No. & OR $(95 \% \mathrm{CI})^{\mathrm{b}}$ & No. & OR $(95 \% \mathrm{CI})^{\mathrm{b}}$ \\
\hline $\begin{array}{l}\text { Any autoimmune } \\
\text { condition } \\
\text { Systemic/connective } \\
\text { tissue }\end{array}$ & 14056 & 973 & $1.29(1.20-1.39)$ & 208 & $1.09(0.94-1.27)$ & 5968 & 574 & $1.50(1.35-1.66)$ & 171 & $1.15(0.97-1.37)$ \\
\hline $\begin{array}{l}\text { Rheumatoid } \\
\text { arthritis }\end{array}$ & 3425 & 237 & ${\underline{1.28(1.11-1.47)^{c}}}^{\mathrm{c}}$ & 56 & $1.23(0.94-1.62)$ & 1480 & 150 & $1.52(1.27-1.81)^{c}$ & 39 & $1.01(0.73-1.41)$ \\
\hline Sjögren's syndrome & 261 & 16 & $1.10(0.66-1.82)$ & $<5$ & $1.14(0.42-3.09)$ & 120 & 15 & $1.78(1.03-3.07)$ & $<5$ & $0.90(0.29-2.85)$ \\
\hline $\begin{array}{l}\text { Systemic lupus } \\
\text { erythematosus }\end{array}$ & 298 & 31 & $\underline{1.92(1.31-2.80)^{c}}$ & 5 & $1.28(0.52-3.12)$ & 117 & 14 & $1.82(1.04-3.16)$ & $<5$ & $0.31(0.04-2.23)$ \\
\hline Sarcoidosis & 101 & 10 & $1.84(0.95-3.56)$ & $<5$ & $0.76(0.11-5.46)$ & 42 & $<5$ & $1.1 \mid(0.34-3.61)$ & 0 & - \\
\hline Systemic sclerosis & 83 & $<5$ & $0.90(0.33-2.47)$ & $<5$ & $0.94(0.13-6.80)$ & 38 & 5 & $2.05(0.80-5.25)$ & $<5$ & $0.93(0.13-6.85)$ \\
\hline $\begin{array}{l}\text { Polymyalgia } \\
\text { rheumatica }\end{array}$ & 1288 & 125 & $\underline{1.73(1.43-2.09)^{c}}$ & 32 & $1.79(1.25-2.57)$ & 518 & 55 & $\underline{1.47(1.11-1.96)}$ & 15 & I.II (0.66-1.86) \\
\hline $\begin{array}{l}\text { Ankylosing } \\
\text { spondylitis }\end{array}$ & 133 & II & $1.43(0.76-2.68)$ & $<5$ & $0.53(0.07-3.84)$ & 59 & 5 & $1.18(0.47-2.93)$ & $<5$ & $2.04(0.64-6.55)$ \\
\hline $\begin{array}{l}\text { Dermatomyositis/ } \\
\text { polymyositis }\end{array}$ & 135 & 7 & $0.91(0.42-1.96)$ & 7 & $\underline{3.97(1.82-8.61)^{c}}$ & 60 & $<5$ & $0.46(0.11-1.90)$ & $<5$ & $0.61(0.08-4.43)$ \\
\hline \multicolumn{11}{|l|}{ Blood } \\
\hline $\begin{array}{l}\text { Autoimmune } \\
\text { haemolytic anaemia }\end{array}$ & 52 & 11 & $\underline{3.74(1.94-7.22)^{c}}$ & $<5$ & $\underline{5.23(1.82-15.0)}$ & 20 & 6 & $\underline{4.12(1.66-10.2)}$ & 6 & $11.9(4.72-30.2)$ \\
\hline \multicolumn{11}{|l|}{ Cardiovascular } \\
\hline Systemic vasculitis & 27 & 10 & $6.23(2.81-13.8)^{c}$ & 0 & - & 8 & $<5$ & $3.49(0.7|-| 7.0)$ & 0 & - \\
\hline $\begin{array}{l}\text { Chronic rheumatic } \\
\text { heart disease }\end{array}$ & 4099 & 239 & $1.01(0.88-1.15)$ & 57 & $0.99(0.76-1.30)$ & 1839 & 173 & $\underline{1.28(1.08-1.51)}$ & 46 & $0.98(0.73-1.33)$ \\
\hline Giant cell arteritis & 427 & 37 & $1.6 \mid(1.14-2.27)$ & $<5$ & $0.36(0.09-1.44)$ & |7| & 16 & $1.28(0.76-2.16)$ & $<5$ & $0.44(0.11-1.77)$ \\
\hline Polyarteritis nodosa & 35 & $<5$ & $1.97(0.68-5.72)$ & 0 & - & 16 & 5 & $\underline{4.31(1.51-12.3)}$ & $<5$ & $2.51(0.33-19.1)$ \\
\hline \multicolumn{11}{|l|}{ Endocrine } \\
\hline Addison's disease & 196 & 12 & $1.05(0.59-1.89)$ & $<5$ & $1.49(0.55-4.04)$ & 92 & 6 & $0.89(0.39-2.03)$ & $<5$ & $0.84(0.21-3.43)$ \\
\hline Graves' disease & 360 & 21 & $1.04(0.66-1.62)$ & 8 & $1.65(0.81-3.35)$ & 150 & 5 & $0.49(0.20-1.20)$ & 5 & $1.26(0.52-3.06)$ \\
\hline $\begin{array}{l}\text { Hashimoto's } \\
\text { thyroiditis }\end{array}$ & 290 & 17 & $1.06(0.65-1.74)$ & $<5$ & $1.07(0.40-2.88)$ & 149 & 10 & $0.97(0.51-1.86)$ & 8 & $1.98(0.96-4.08)$ \\
\hline \multicolumn{11}{|l|}{ Skin } \\
\hline Psoriasis & 1543 & 95 & $1.07(0.87-1.33)$ & 19 & $0.91(0.58-1.44)$ & 689 & 57 & $1.16(0.88-1.53)$ & 23 & $1.32(0.87-2.01)$ \\
\hline Alopecia areata & 99 & 6 & $1.16(0.50-2.66)$ & $<5$ & $0.8 \mid(0.1 \mid-5.76)$ & 50 & $<5$ & $1.23(0.44-3.42)$ & $<5$ & $0.73(0.10-5.29)$ \\
\hline Pemphigus & 26 & $<5$ & $0.69(0.09-5.13)$ & 0 & - & 11 & 0 & - & 0 & - \\
\hline $\begin{array}{l}\text { Localised } \\
\text { scleroderma }\end{array}$ & 178 & | | & I.II (0.60-2.06) & $<5$ & $0.43(0.06-3.07)$ & 94 & 5 & $0.76(0.31-1.89)$ & 6 & $2.34(1.02-5.37)$ \\
\hline $\begin{array}{l}\text { Discoid lupus } \\
\text { erythematosus }\end{array}$ & 149 & 5 & $0.61(0.25-1.50)$ & $<5$ & $0.51(0.07-3.65)$ & 63 & 9 & $2.06(1.02-4.17)$ & 0 & - \\
\hline \multicolumn{11}{|l|}{ Gastrointestinal } \\
\hline Coeliac disease & 54 & $<5$ & $0.63(0.15-2.60)$ & $<5$ & $4.19(1.30-13.5)$ & 26 & $<5$ & $0.5 \mid(0.07-3.77)$ & 0 & - \\
\hline Crohn's disease & 316 & 26 & $1.43(0.95-2.15)$ & $<5$ & $\overline{0.67(0.21-2.09)}$ & 120 & 14 & $1.60(0.9 \mid-2.78)$ & 7 & $2.18(1.01-4.71)$ \\
\hline Ulcerative colitis & 504 & 50 & $1.72(1.28-2.31)^{c}$ & 5 & $0.72(0.30-1.74)$ & 229 & 22 & $1.33(0.86-2.07)$ & 7 & $\overline{1.18(0.55-2.51)}$ \\
\hline Pernicious anaemia & 2008 & 177 & $1.57(1.34-1.84)^{c}$ & 21 & $0.74(0.48-1.14)$ & 886 & 148 & $\underline{2.38(1.98-2.86)^{c}}$ & 25 & I.II (0.74-1.67) \\
\hline \multicolumn{11}{|l|}{ Nervous system } \\
\hline Multiple sclerosis & 185 & 7 & $0.68(0.32-1.45)$ & $<5$ & $0.77(0.19-3.12)$ & 55 & $<5$ & $0.55(0.13-2.22)$ & 0 & - \\
\hline Myasthenia gravis & 115 & 8 & $1.20(0.58-2.49)$ & 0 & - & 54 & $<5$ & $0.25(0.04-1.86)$ & $<5$ & $2.26(0.7 \mid-7.24)$ \\
\hline
\end{tabular}

$\mathrm{Cl}=$ confidence interval; $\mathrm{OR}=$ odds ratio; SEER = Surveillance Epidemiology and End Results. Observations, in which the number of exposed patients or controls is between one and four, are listed as ' $<5$ ' to reserve subjects' anonymity, in accordance with the SEER-Medicare data use agreement. Associations significant at the $P<0.05$ level are underlined. For consistency across tables, all ORs are shown to two decimal places (or three significant figures if the OR $\geq 10.0$ ). Nonetheless, we note that many estimates are based on few exposed cases. ${ }^{\mathrm{a} O R s}$ and $95 \%$ Cls are adjusted for age (67-69, 70-74, 75-79, 80-84 and 85-99 years), gender, selection year (I987-1996, 1997-1999, $2000-2001,2002)$, race (white, non-white) and number of physician claims (0-20, $21-57,58-127, \geqslant 128)$. ${ }^{b}$ ORs and $95 \%$ Cls are adjusted for age $(67-69,70-74,75-79$,

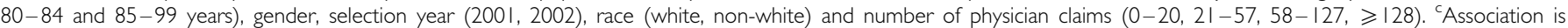
significant at $P<0.0005$ (Bonferroni correction for 108 comparisons). 
Table 3 Associations between selected autoimmune conditions and myelodysplastic syndrome and chronic myeloid disorder with exclusions of time intervals before diagnosis/selection

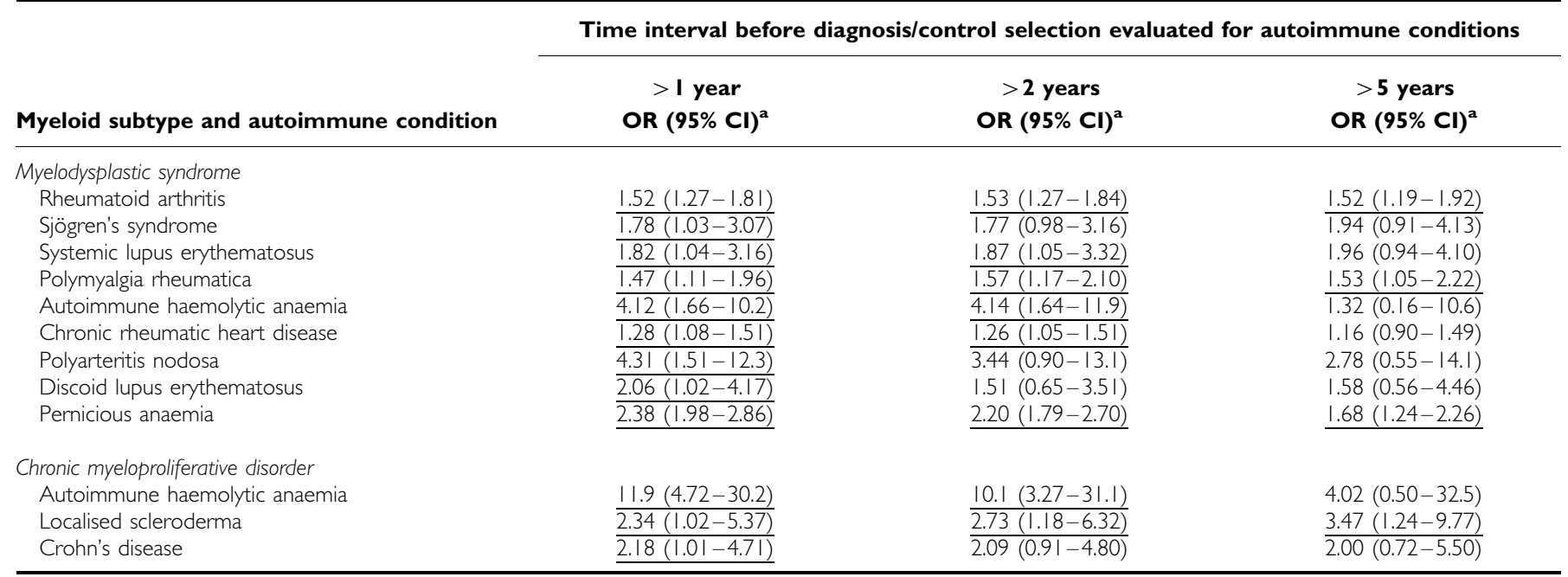

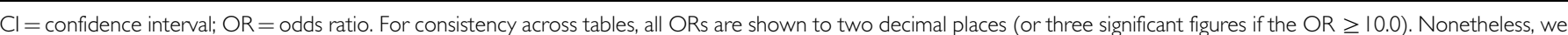
note that many estimates are based on few exposed cases. Associations significant at the $P<0.05$ level are underlined. ${ }^{\mathrm{a}} \mathrm{ORs}$ and $95 \% \mathrm{Cls}$ are adjusted for age (67-69, 70-74, $75-79,80-84$ and $85-99$ years), gender, race (white, non-white), number of physician claims $(0-20,21-57,58-127, \geqslant 128)$ and selection year (2001, 2002)

Several case reports have described AML and MDS occurring in patients with rheumatoid arthritis, mainly after treatment with azathioprine (Alexson and Brandt, 1977; Kwong et al, 1998) or methotrexate (Espinosa et al, 2002; Okamoto et al, 2004). However, non-steroidal anti-inflammatory drugs, used in the treatment of rheumatoid arthritis and other inflammatory conditions included in our study, appear to decrease the risk of myeloid leukaemia (Pogoda et al, 2005), suggesting that their use is unlikely to explain the excess risk of myeloid malignancies. Unfortunately, we lacked treatment information and were, therefore, unable to determine whether the observed increased risks of AML and MDS were related to therapy.

We also observed an increased risk of AML with systemic lupus erythematosus, which might be attributed partly to the use of immune-modulating treatments, such as azathioprine (Alexson and Brandt, 1977; Kwong et al, 1998). Another systemic autoimmune condition associated with an increased risk of AML and CML (and to a lesser extent MDS) was polymyalgia rheumatica. Some studies have reported polymyalgia rheumatica to occur subsequent to diagnosis of MDS (Mok et al, 1996; Espinosa et al, 2002), and polymyalgia rheumatica has been reported to precede AML (Anton, 2007). Giant cell arteritis, a condition closely related to polymyalgia rheumatica, was more weakly associated with AML in our study. Among the other autoimmune conditions affecting the cardiovascular system, only systemic vasculitis remained associated with AML after adjustment for multiple comparisons. To our knowledge, AML has not been reported in patients with systemic vasculitis, though large-vessel arteritis has been reported in patients with MDS (Steurer et al, 2004).

In our study, AIHA significantly increased the risk for all of the myeloid malignancies. Autoimmune haemolytic anaemia is considered to be a complication of several lymphoproliferative disorders (Ekstrom Smedby et al, 2008). Although case reports describe AIHA with MDS (Giagounidis et al, 2005), AML (Deutsch et al, 2003) and CML (Arbaje and Beltran, 1990), we found AIHA to occur antecedent to these diagnoses. Consistent with our findings, AIHA was found to be associated with an eight-fold increased risk of AML in a large cohort study in Sweden (Soderberg et al, 2006). As MDS and MPD are indolent and may be present years before diagnosis, it is possible that AIHA arose as a result of these conditions. This explanation is less likely for AML and CML, and it is possible that AIHA acts late in a causal pathway to promote the development of these malignancies.

Ulcerative colitis was associated with an increased risk of AML, in keeping with a Swedish population-based cohort study which found an $80 \%$ increase in ulcerative colitis patients (Askling et al, 2005a). However, other cohort studies found no such relation between ulcerative colitis and risk of AML (Bernstein et al, 2001; Winther et al, 2004; Hemminki et al, 2008). Pernicious anaemia has been reported antecedent to AML (Hsing et al, 1993), consistent with the association we observed. Dermatomyositis/ polymyositis was associated strongly with CML. Although these conditions manifest commonly in cancer patients (Stockton et al, 2001), the association with CML remained elevated even when the 5 -year period before diagnosis was excluded, indicating that dermatomyositis/polymyositis may also precede CML.

There are several possible explanations for these associations with myeloid malignancies. First, as mentioned earlier, certain treatments for autoimmune conditions, such as azathioprine, could increase the risk of developing MDS or AML. However, the associations with AML were not specific to autoimmune conditions treated with these medications. Second, some autoimmune conditions could share common genetic predispositions with myeloid malignancies. For example, carriers of the human leucocyte antigen-B27 are predisposed to some autoimmune conditions and AML (Au et al, 2001). Polymorphisms of interleukin-1 have been associated with several autoimmune conditions, and polymorphisms in the interleukin 1 receptor antagonist are associated with AML (Demeter et al, 1996). Finally, an intriguing possibility is that autoimmune conditions could infiltrate the bone marrow and cause damage to the myeloid precursor cells that differentiate into blood cells.

The SMAHRT study has several strengths including the large number of individuals with myeloid malignancies, the populationbased sampling of cases and the random selection of controls from the population. The SEER database covers $\sim 25 \%$ of the US population (Warren et al, 2002) making our study representative of the elderly US population. In addition, the availability of outpatient, inpatient and physician claims allowed us to investigate the associations between a range of autoimmune conditions and 
myeloid malignancies. Our study also has some limitations. First, the small number of cases and controls with some uncommon autoimmune conditions limit the precision of our estimates, so cautious interpretation is indicated. Second, as claim files were utilised in place of a definite diagnosis, autoimmune conditions which required few physician visits could have been underestimated. Third, despite our exclusion of a 1-year period before cancer diagnosis, some autoimmune conditions could have been the result of the myeloid malignancy. This seems unlikely for AML and CML, but could explain some associations with the more indolent conditions, MDS and MPD. Fourth, as MDS and MPD are a heterogeneous group of diseases, some associations could have been masked by combining these conditions into one category. Unfortunately, we did not have sufficient sample sizes to investigate risk by more specific subtypes. Fifth, cases and controls differed according to some factors, such as race and frequency of Medicare claims, which could have led to differences in the prevalence of autoimmune conditions or our ability to detect their presence. However, we adjusted for these differences in our statistical models. Finally, as some of the numerous associations investigated may have occurred by chance, we therefore used a Bonferroni correction to highlight those associations least likely to be due to chance.

In summary, certain autoimmune conditions were associated with increased risks of MDS, MPD, CML, and in particular AML, possibly due to a common genetic predisposition, the effects of medications used to treat autoimmune conditions, or direct damage of the bone marrow by autoimmune conditions.

\section{ACKNOWLEDGEMENTS}

This study used the linked SEER-Medicare database. The interpretation and reporting of these data are the sole responsibility of the authors. The authors acknowledge the efforts of the Applied Research Program, NCI; the Office of Research, Development and Information, Centers for Medicare and Medicaid Services; Information Management Services, Inc.; and the Surveillance, Epidemiology, and End Results (SEER) Program tumor registries in the creation of the SEER-Medicare database. This research was supported by the Intramural Research Program of the National Cancer Institute. The Research and Development Office, Northern Ireland, funded Dr Lesley Anderson to participate in the Cancer Prevention Fellowship Program, Office of Preventive Oncology, National Cancer Institute. The authors thank Winnie Ricker and Ruth Parsons, Information Management Services, Rockville, MD for constructing the dataset, and Joan Warren, Division of Cancer Control and Population Sciences, National Cancer Institute, MD, for her assistance with the SEER-Medicare dataset.

\section{REFERENCES}

Alexson E, Brandt KD (1977) Acute leukemia after azathioprine treatment of connective tissue disease. Am J Med Sci 273: 335-340

Anderson LA, Pfeiffer R, Warren JL, Landgren O, Gadalla S, Berndt SI, Ricker W, Parsons R, Wheeler W, Engels EA (2008) Hematopoietic malignancies associated with viral and alcoholic hepatitis. Cancer Epidemiol Biomarkers Prev 17: 3069-3075

Anton E (2007) More on polymyalgia rheumatica (PMR) as a paraneoplastic rheumatic syndrome in the elderly (bicytopenia and PMR preceding acute myeloid leukemia). J Clin Rheumatol 13: 114

Arbaje YM, Beltran G (1990) Chronic myelogenous leukemia complicated by autoimmune hemolytic anemia. Am J Med 88: $197-199$

Askling J, Brandt L, Lapidus A, Karlen P, Bjorkholm M, Lofberg R, Ekbom A (2005a) Risk of haematopoietic cancer in patients with inflammatory bowel disease. Gut 54: 617-622

Askling J, Fored CM, Baecklund E, Brandt L, Backlin C, Ekbom A, Sundstrom C, Bertilsson L, Coster L, Geborek P, Jacobsson LT, Lindblad S, Lysholm J, Rantapaa-Dahlqvist S, Saxne T, Klareskog L, Feltelius N (2005b) Haematopoietic malignancies in rheumatoid arthritis: lymphoma risk and characteristics after exposure to tumour necrosis factor antagonists. Ann Rheum Dis 64: 1414-1420

$\mathrm{Au}$ WY, Hawkins BR, Cheng N, Lie AK, Liang R, Kwong YL (2001) Risk of haematological malignancies in HLA-B27 carriers. Br J Haematol 115: $320-322$

Bernstein CN, Blanchard JF, Kliewer E, Wajda A (2001) Cancer risk in patients with inflammatory bowel disease: a population-based study. Cancer 91: $854-862$

Dalamaga M, Petridou E, Cook FE, Trichopoulos D (2002) Risk factors for myelodysplastic syndromes: a case-control study in Greece. Cancer Causes Control 13: 603-608

Demeter J, Messer G, Ramisch S, Mee JB, di Giovine FS, Schmid M, Herrmann F, Porzsolt F (1996) Polymorphism within the second intron of the IL-1 receptor antagonist gene in patients with hematopoietic malignancies. Cytokines Mol Ther 2: 239-242

Descatha A, Jenabian A, Conso F, Ameille J (2005) Occupational exposures and haematological malignancies: overview on human recent data. Cancer Causes Control 16: 939-953

Deutsch M, Dourakis SP, Papanikolopoulos K, Belegrati M, Kalmantis T (2003) Autoimmune hemolytic anemia in a patient with acute myelocytic leukemia. Am J Hematol 74: 147

Ekstrom Smedby K, Vajdic CM, Falster M, Engels EA, Martinez-Maza O, Turner J, Hjalgrim H, Vineis P, Seniori Costantini A, Bracci PM, Holly
EA, Willett E, Spinelli JJ, La Vecchia C, Zheng T, Becker N, De Sanjose S, Chiu BC, Dal Maso L, Cocco P, Maynadie M, Foretova L, Staines A, Brennan P, Davis S, Severson R, Cerhan JR, Breen EC, Birmann B, Grulich AE, Cozen W (2008) Autoimmune disorders and risk of nonHodgkin lymphoma subtypes: a pooled analysis within the InterLymph Consortium. Blood 111: 4029-4038

Espinosa G, Font J, Munoz-Rodriguez FJ, Cervera R, Ingelmo M (2002) Myelodysplastic and myeloproliferative syndromes associated with giant cell arteritis and polymyalgia rheumatica: a coincidental coexistence or a causal relationship? Clin Rheumatol 21: 309-313

Giagounidis AA, Haase S, Germing U, Heinsch M, Aul C (2005) Autoimmune disorders in two patients with myelodysplastic syndrome and 5q deletion. Acta Haematol 113: 146-149

Hemminki K, Li X, Sundquist J, Sundquist K (2008) Cancer risks in ulcerative colitis patients. Int J Cancer 123: 1417-1421

Hsing AW, Hansson LE, McLaughlin JK, Nyren O, Blot WJ, Ekbom A, Fraumeni JF (1993) Pernicious anemia and subsequent cancer. A population-based cohort study. Cancer 71: 745-750

Jaffe ES, Harris NL, Stein H, Vardiman JW (2001) Pathology and Genetics of Tumours of Hematopoietic and Lymphoid Tissues. World Health Organization Classification of Tumours. IARC: Lyon

Kasim K, Levallois P, Abdous B, Auger P, Johnson KC (2005) Lifestyle factors and the risk of adult leukemia in Canada. Cancer Causes Control 16: $489-500$

Kwong YL, Au WY, Liang RH (1998) Acute myeloid leukemia after azathioprine treatment for autoimmune diseases: association with $-7 / 7 \mathrm{q}-$. Cancer Genet Cytogenet 104: 94-97

Mok CC, Lau CS, Kumana CR (1996) Polymyalgia rheumatica as the rheumatological manifestation of myelodysplastic syndrome in a Chinese patient. Br J Rheumatol 35: 496-497

Nisse C, Haguenoer JM, Grandbastien B, Preudhomme C, Fontaine B, Brillet JM, Lejeune R, Fenaux P (2001) Occupational and environmental risk factors of the myelodysplastic syndromes in the North of France. $\mathrm{Br} \mathrm{J}$ Haematol 112: 927-935

Okamoto H, Teramura M, Kamatani N (2004) Myelodysplastic syndrome associated with low-dose methotrexate in rheumatoid arthritis. Ann Pharmacother 38: $172-173$

Pogoda JM, Katz J, McKean-Cowdin R, Nichols PW, Ross RK, Preston-Martin S (2005) Prescription drug use and risk of acute myeloid leukemia by French-American-British subtype: results from a Los Angeles County case-control study. Int $J$ Cancer 114: $634-638$ 
Preston-Martin S, Thomas DC, Yu MC, Henderson BE (1989) Diagnostic radiography as a risk factor for chronic myeloid and monocytic leukaemia (CML). Br J Cancer 59: 639-644

Soderberg KC, Jonsson F, Winqvist O, Hagmar L, Feychting M (2006) Autoimmune diseases, asthma and risk of haematological malignancies: nationwide case-control study in Sweden. Eur J Cancer 42(17): 3028 - 3033

Steurer M, Fritsche G, Tzankov A, Gotwald T, Sturm W, Konwalinka G, Gruber J (2004) Large-vessel arteritis and myelodysplastic syndrome: report of two cases. Eur J Haematol 73: 128-133

Stockton D, Doherty VR, Brewster DH (2001) Risk of cancer in patients with dermatomyositis or polymyositis, and follow-up implications: a Scottish population-based cohort study. Br J Cancer 85: 41 - 45

Strom SS, Gu Y, Gruschkus SK, Pierce SA, Estey EH (2005) Risk factors of myelodysplastic syndromes: a case-control study. Leukemia 19: 1912-1918

Voulgarelis M, Giannouli S, Ritis K, Tzioufas AG (2004) Myelodysplasiaassociated autoimmunity: clinical and pathophysiologic concepts. Eur J Clin Invest 34: 690-700
Warren JL, Klabunde CN, Schrag D, Bach PB, Riley GF (2002) Overview of the SEER-Medicare data: content, research applications, and generalizability to the United States elderly population. Med Care 40: IV-3 - IV -18

Winther KV, Jess T, Langholz E, Munkholm P, Binder V (2004) Long-term risk of cancer in ulcerative colitis: a population-based cohort study from Copenhagen County. Clin Gastroenterol Hepatol 2: $1088-1095$

Xu X, Talbott EO, Zborowski JV, Rager JR (2007) Cigarette smoking and the risk of adult leukemia: results from the Three Mile Island cohort study. Arch Environ Occup Health 62: 131-137

Zheng W, Linet MS, Shu XO, Pan RP, Gao YT, Fraumeni Jr JF (1993) Prior medical conditions and the risk of adult leukemia in Shanghai, People's Republic of China. Cancer Causes Control 4: 361 - 368

Zintzaras E, Voulgarelis M, Moutsopoulos HM (2005) The risk of lymphoma development in autoimmune diseases: a meta-analysis. Arch Intern Med 165: 2337-2344 